\title{
Biotyping, serotyping and phage typing of Streptococcus faecalis isolated from dental plaque in the human mouth
}

\author{
C. J. SMYTH, HELEN MATTHEWS, M. K. HALPENNY*, H. BRANDIS $†$ and G. COLMAN‡
}

Department of Microbiology, Moyne Institute, Trinity College, Dublin 2, *Department of Oral Surgery, Dublin Dental Hospital, Lincoln Place, Dublin 2, Eire, †Institut für Medizinische Mikrobiologie und Immunologie der Universität Bonn, Sigmund-Freud Strasse 25, D-5300 Bonn 1, Federal Republic of Germany and $¥$ Streptococcus Reference Unit, Division for Hospital Infection, Central Public Health Laboratory, 61 Colindale Avenue, London NW9 5HT

\begin{abstract}
Summary. Thirty Streptococcus faecalis isolates from mixed dental plaque samples were classified into four groups on the basis of biotype, tetracycline susceptibility, phage type and serotype combinations. The organisms were from patients on haemodialysis, from staff of the dialysis unit, and from controls. Three biotypes were distinguished by seven biochemical tests: production of acid from inositol, sucrose and xylose; rapid or delayed production of acid from sorbitol; gelatin liquefaction; and production of alkaline phosphatase and $\beta$-galactosidase. With a set of eight typing antisera for $S$. faecalis, 15 strains were non-typable, 12 were serotype 1 and three were serntype 19. With a set of 17 bacteriophages specific for S. faecalis, all of the oral isolates were typable; $40 \%$ were lysotype $I_{1}$ and the remainder lysotype $V_{6 b}$. On the basis of biotype-serotype-phage-type combinations, indications of possible spread of strains between haemodialysis patients and dialysis unit staff were obtained. Biotyping and serotyping of 13 German isolates of $S$. faecalis of phage type $\mathrm{I}_{1}$ from four clinical sources and tripartite typing of three control strains provided additional evidence for the potential of biotyping in distinguishing between strains of identical serotype and phage type. One oral isolate of $S$. faecium was of phage type XX. None of the oral isolates of $S$. faecalis, of which 14 exhibited delayed sorbitol fermentation, reacted with group-G streptococcal grouping reagents or antiserum. Slow sorbitol fermentation does not appear to be a definitive phenotypic marker for $S$. faecalis strains possessing antigens that react with both group-D and group- $G$ grouping reagents.
\end{abstract}

\section{Introduction}

Several methods that may have potential for epidemiological studies have been described for the typing of enterococcal group-D streptococci, particularly Streptococcus faecalis. The serological typing system of Sharpe and Shattock (1952) divided $S$. faecalis and its varieties into 12 serotypes to which $85.4 \%$ of 267 isolates could be allocated. Up to $94 \%$ of $S$. faecalis isolates in other studies have been serotyped by this method (Plećeaš, 1967; Plećeaš et al., 1968). However, of 198 isolates of $S$. faecalis from various clinical sources serotyped at the Division of Hospital Infection during the 3-year period 1983-1985, 17\% were non-typable and $45 \%$ reacted with type- 9 serum alone or additionally with either type- 4 or type-19 serum (G. Colman,

Received 1 May 1986; accepted 12 May 1986. unpublished data). This serotyping scheme therefore appears to lack discrimination for epidemiological purposes. Recently, the occurrence of $S$. faecalis isolates that reacted with both group-D and group-G grouping reagents has been reported from several locations (Birch et al., 1984, 1985; Hopfer et al., 1985).

Several reports exist on phage typing of enterococci (Hérmán and Hoch, 1971; Hoch and Hérmán, 1971; Caprioli et al., 1975; Plećeaš, 1979, 1982). Pooled phages can be used for rapid group and species identification (Plećeaš and Brandis, 1974a and $b$ ). With the typing scheme developed by Plećeaš (1979), 89.9\% of 439 enterococcal isolates could be typed. This scheme has been modified and enlarged by Brandis et al. (1985). With 17 phages specific for $S$. faecalis and seven phages specific for S. faecium, it is possible to distinguish 22 lysotypes with $S$. faecalis and 12 lysotypes with $S$. faecium. 
Within several lysotypes subtypes can be recognised.

Little attempt seems to have been made to use biotyping for epidemiological purposes, although the data of Facklam (1972), Parker and Ball (1976) and Colman and Ball (1984) suggest that strains of $S$. faecalis from human sources show a degree of heterogeneity in certain biochemical and physiological tests. The taxonomic validity of varieties or subspecies of $S$. faecalis is questionable (Deibel, 1964; Jones et al., 1972; Jones, 1978; Feltham, 1979; Collins and Jones, 1979), but the variety or subspecies liquefaciens continues to be distinguished by gelatinase production and zymogenes by the presence of $\beta$ haemolysis, although these would be better regarded as "functional biotypes" (Jones $e t$ al., 1972).

In a survey of oral carriage of enterococci amongst haemodialysis patients, dialysis unit staff, patients with toothache and University students and personnel, Smyth et al. (in press) showed that the incidence of oral carriage of enterococci in dental plaque was statistically significantly higher in a group of hospital patients on haemodialysis and their attendant dialysis unit staff than in two other groups of haemodialysis outpatients and their attendant staffs at two separate hospitals $(\mathrm{p}<0.001)$. A combined biotyping, serotyping and phagetyping study was performed (i) to try to identify any epidemiological link between the haemodialysis patients and the dialysis unit staffs and (ii) to characterise oral isolates of enterococci from dental plaque to determine any variation in lysotype, serotype or biotype amongst such strains.

\section{Materials and methods}

\section{Bacterial strains}

The oral enterococcal isolates (table I) were obtained from mixed plaque samples from 21 out of 209 subjects examined (Smyth et al., 1986). Isolates were presumptively identified as enterococci by Gram's stain, by growth in bile-aesculin medium, $6.5 \% \mathrm{w} / \mathrm{v}$ salt tolerance broth and $S$. faecalis broth (Difco), and by arginine hydrolysis (Facklam, 1972; Facklam and Carey, 1985). Serological confirmation as group-D streptococci was made by the Phadebact ${ }^{\circledR}$ Strep D coagglutination reagent (Pharmacia Diagnostics, Uppsala, Sweden) with overnight ToddHewitt-broth (Oxoid) cultures.

As a result of preliminary tests to determine the minimum inhibitory concentrations (MIC) of antibiotics, isolates were divided into two phenotypes according to their ability to grow in the presence of tetracycline $>2-4$ $\mu \mathrm{g} / \mathrm{ml}$ in Diagnostic Sensitivity Test (DST) agar (Oxoid). Accordingly, 31 enterococcal isolates from the 21 subjects yielding enterococci were categorised as tetracycline- sensitive $\left(\mathrm{Tet}^{\mathrm{s}}\right)$ and tetracycline-resistant $\left(\mathrm{Tet}^{\mathrm{r}}\right)$. Ten subjects yielded both $\mathrm{Tet}^{\mathrm{s}}$ and $\mathrm{Tet}^{\mathrm{r}}$ isolates (table I).

In addition, 13 German $S$. faecalis isolates of phage type $I_{1}$, of which nine were from urine, two from vaginal swabs and one each from a wound swab and an umbilical swab, were examined for tetracycline susceptibility, biotype and serotype (see Results).

$S$. faecalis strain ATCC 19433 was used as a reference organism to control media and test reactions. S. faecalis strains M439 and M440 (Van Embden et al., 1977; Engel et al., 1979), both of which possess plasmid-mediated tetracycline resistance and erythromycin resistance, were obtained from Dr D. G. Groothuis, Rijks Instituut voor Volksgezondheid en Milieuhygien, Bilthoven, The Netherlands. These strains were used as controls in the determination of MIC values for different tetracyclines.

\section{Species identification}

The following tests were used for species identification: production of acid from arabinose, glycerol (aerobically and anaerobically), lactose, mannitol, raffinose, salicin, sorbitol, sucrose and trehalose; haemolysis on humanblood agar $(5 \% \mathrm{v} / \mathrm{v}$ in Oxoid Columbia Blood Agar Base); tellurite tolerance (DST agar containing potassium tellurite $0.25 \mathrm{mg} / \mathrm{ml}$ ); pyruvate fermentation according to the method of Gross et al. (1975); gelatin liquefaction in nutrient gelatin deeps and with Chargel discs (Oxoid) on DST agar slopes (incubated for up to 14 days at $37^{\circ} \mathrm{C}$ ); and aesculin hydrolysis (Facklam, 1972; Cowan, 1974; Gross et al., 1975; Jones, 1978; Facklam and Carey, 1985). Sugar breakdown tests were performed in brothbased sugars with bromocresol purple as indicator (Edwards and Ewing, 1972).

\section{Biotyping}

Each of the enterococcal isolates from dental plaque was tested for the following: production of acid from adonitol, amygdalin, cellobiose, dulcitol, fructose, galactose, inulin, maltose, melibiose, rhamnose, and sorbose; production of acid from inositol; production of arginine, lysine and ornithine decarboxylases (Møller, 1955); and production of acid from mucic acid (Edwards and Ewing, 1972).

The API-20 Strep Kit (API System SA, La Balme-lesGrottes, France) was also used for biotyping strains (Colman and Ball, 1984). The manufacturer's instructions were followed for inoculation of kits and reading of tests, except that Columbia human blood agar $5 \% \mathrm{v} / \mathrm{v}$ plates, instead of sheep blood agar plates, were used for the anaerobic growth of inocula. Haemolysin production was assessed after aerobic incubation and after incubation anaerobically in a GasPak anaerobic jar system (Baltimore Biological Laboratories). Incubation of the kits was continued for up to 5 days to examine for delayed production of acid from sorbitol.

\section{Serotyping}

The $S$. faecalis isolates were serotyped by agar gel 
diffusion tests with specific absorbed sera to serotypes 1, 3, 4, 5, 6, 8, 9 and 19 (Sharpe and Shattock, 1952), i.e., eight of the 12 serotypes originally described which accounted for $94.8 \%$ of the clinical and faecal $S$. faecalis examined therein. Strains that did not yield a precipitate with any of these sera were designated "non-typable". Strains were serotyped after being encoded so that the origins of strains were unknown to the person performing the tests.

\section{Phage typing}

Lysotyping of the $S$. faecalis strains and of the one $S$. durans isolate was performed according to the scheme of Plećeaš (1979) as modified by Brandis et al. (1985), with 17 phages for the former and seven for the latter. The identity of species was also confirmed by the use of pooled phages (Plećeaš and Brandis, 1974a and $b$ ). As with the serotyping, phage typing was performed in a blind manner with encoded strains. Streptococci were grown in Tryptose Phosphate Broth (Difco) for $2 \mathrm{~h}$ at $37^{\circ} \mathrm{C}$ and then seeded by flooding onto plates of Tryptose Phosphate agar containing $5 \mathrm{~g}$ yeast extract (Difco) per litre. Phages were applied at routine test dilution. Only strong lytic reactions (confluent or $3+$ ) were considered positive.

\section{MIC values}

The susceptibilities of the Dublin enterococcal isolates, the German $S$. faecalis strains and of $S$. faecalis strains ATCC 19433, M439 and M440 to five tetracyclines were

Table I. Sources and identification of enterococcal isolates from dental plaque

\begin{tabular}{|c|c|c|c|c|}
\hline \multirow{2}{*}{$\begin{array}{l}\text { Strain } \\
\text { no.* }\end{array}$} & \multirow[b]{2}{*}{ Species $\dagger$} & \multicolumn{2}{|r|}{ Subject } & \multirow[b]{2}{*}{ Location $\ddagger$} \\
\hline & & Sex/Age & Study group & \\
\hline $11018 \mathrm{~S}$ & S. faecalis & $\mathrm{M} / 41$ & Laboratory personnel & University \\
\hline 11018R & S. faecalis var. liquefaciens & & & \\
\hline I1025R & S. faecalis var. liquefaciens & $\mathrm{F} / 21$ & Student & University \\
\hline $11027 \mathrm{~S}$ & S. faecalis & $\mathrm{M} / 24$ & Student & University \\
\hline $12019 \mathrm{~S}$ & S. faecalis & $\mathrm{M} / 23$ & Toothache patient & $\mathrm{DDH}$ \\
\hline 12019R & S. faecalis var. liquefaciens & & & \\
\hline $12038 \mathrm{~S}$ & S. faecalis & $\mathrm{F} / 27$ & Toothache patient & $\mathrm{DDH}$ \\
\hline I2038R & S. faecalis var. liquefaciens & & & \\
\hline 12054R & S. faecalis var. liquefaciens & $\mathrm{F} / 49$ & Toothache patient & DDH \\
\hline $13002 \mathrm{~S}$ & S. faecalis & $\mathrm{M} / 38$ & Haemodialysis outpatient & Hospital D \\
\hline $13002 R$ & S. faecalis var. liquefaciens & & & \\
\hline $13008 \mathrm{~S}$ & S. faecalis & $\mathrm{M} / 32$ & Haemodialysis outpatient & Hospital D \\
\hline 13008R & S. faecalis & & & \\
\hline $13043 \mathrm{~S}$ & S. faecalis & $\mathrm{M} / 59$ & Haemodialysis outpatient & Hospital D \\
\hline 13043R & S. faecalis var. liquefaciens & & & \\
\hline $14002 \mathrm{~S}$ & S. faecalis & $\mathrm{F} / 27$ & Dialysis unit staff & Hospital D \\
\hline $15006 \mathrm{~S}$ & S. durans§ & $\mathrm{F} / 23$ & Haemodialysis outpatient & Hospital X \\
\hline 15006R & S. faecalis & & & \\
\hline $15010 \mathrm{R}$ & S. faecalis & $\mathrm{M} / 20$ & Haemodialysis outpatient & Hospital X \\
\hline I6005R & S. faecalis var. liquefaciens & $\mathrm{F} / 26$ & Dialysis unit staff & Hospital X \\
\hline $17001 S$ & S. faecalis & $\mathrm{F} / 16$ & Haemodialysis inpatient & Hospital H \\
\hline $17001 \mathrm{R}$ & S. faecalis var. liquefaciens & & & \\
\hline 17002R & S. faecalis var. liquefaciens & $\mathrm{M} / 62$ & Haemodialysis inpatient & Hospital H \\
\hline 17003R & S. faecalis var. liquefaciens & $\mathbf{M} / 35$ & Haemodialysis inpatient & Hospital H \\
\hline $17004 S$ & S. faecalis & $\mathrm{F} / 38$ & Haemodialysis inpatient & Hospital H \\
\hline $17009 \mathrm{~S}$ & S. faecalis & $\mathbf{M} / 39$ & Haemodialysis inpatient & Hospital H \\
\hline $18003 \mathrm{~S}$ & S. faecalis & $F / 26$ & Dialysis unit staff & Hospital H \\
\hline 18003R & S. faecalis & & & \\
\hline $18004 S$ & S. faecalis & $\mathrm{F} / 26$ & Dialysis unit staff & Hospital $\mathrm{H}$ \\
\hline 18004R & S. faecalis var. liquefaciens & & & \\
\hline $18005 \mathrm{~S}$ & S. faecalis & $\mathrm{F} / 27$ & Dialysis unit staff & Hospital H \\
\hline
\end{tabular}

${ }^{*} \mathrm{~S}=$ tetracycline-sensitive; $\mathrm{R}=$ tetracycline-resistant; isolates with the same strain no. are from the same subject.

$\dagger S$. faecalis var. liquefaciens is used in the sense of a biotype.

‡University = Department of Microbiology, Trinity College; $\mathrm{DDH}=$ Dublin Dental Hospital; Hospitals D, X and $\mathrm{H}$ are three hospitals in the Dublin area (Smyth et al., 1986)

§Also known as $S$. faecium var. durans 
determined by the agar dilution method (Washington and Sutter, 1980). Stock solutions of tetracycline, oxytetracycline, chlortetracycline, doxycycline and minocycline were prepared in ethanol $50 \% \mathrm{v} / \mathrm{v}$ and dilutions made in sterile distilled water (Anhalt and Washington, 1980). Two-fold dilution series were made so that strains with a Tet $^{\mathrm{r}}$ phenotype were tested over a range of antibiotic concentrations from $4 \mu \mathrm{g} / \mathrm{ml}$ to $128 \mu \mathrm{g} / \mathrm{ml}$; for strains with a Tet ${ }^{\mathrm{s}}$ phenotype, the range of concentrations was 0.0625 $8 \mu$ g.ml. Control plates contained sterile distilled water. Plates were inoculated with 1 in 100 dilutions of overnight, Todd-Hewitt broth cultures using a Steer's inoculator and were incubated for $18-20 \mathrm{~h}$ at $37^{\circ} \mathrm{C}$. The MIC value was read as the lowest concentration of antibiotic which gave complete inhibition of growth.

\section{Serogrouping with group- $D$ and group- $G$ streptococ- cal reagents.}

Latex agglutination tests with Streptex ${ }^{\circledR}$ (Wellcome Diagnostics) streptococcal grouping reagents were done to examine oral enterococcal isolates for the presence of antigens reactive with the group-D and group-G reagents. Tests were performed as recommended by the manufacturer with Todd-Hewitt broth cultures, incubated overnight, for extraction with the Streptex enzyme reagent. In addition, precipitin-ring tests were also performed by standard procedures using antigen extracts obtained with hot $\mathrm{HCl}$ (Lancefield extract), hot water (autoclave extract) and pronase (protease from S. griseus, type XXI, Sigma Chemical Co.), and streptococcal grouping antisera for groups D and G (Wellcome Diagnostics). Stock
S. faecalis cultures showing both D and G reactions, strain ATCC 19433 (group D) and strain NCTC 5969 (group G) were used as controls.

\section{Results \\ Species identification}

All but one of the 31 enterococcal isolates from dental plaque was $S$. faecalis or its biotype variety liquefaciens (table I). The remaining isolate $15006 \mathrm{~S}$ was identified as $S$. durans ( $S$. faecium var. durans). The species identifications were later confirmed by the use of pooled phages (Plećeaš and Brandis, $1974 a$ and $b$ ). Ten of the 21 individuals carrying enterococci in their dental plaque harboured more than one tetracycline phenotype or biotype of $S$. faecalis or species of enterococcus. Seven carried the combination $S$. faecalis and $S$. faecalis var. liquefaciens. Two individuals carried $\mathrm{Tet}^{\mathrm{r}}$ and $\mathrm{Tet}^{\mathrm{s}}$ variants of $S$. faecalis. Moreover, the Tet $^{\mathrm{r}}$ isolates 13008R and $18003 \mathrm{R}$ from these latter individuals, and the Tet $^{r}$ isolates 15006R and 15010R differed from the other $S$. faecalis isolates by not producing acid from sucrose. All of the $S$. faecalis var. liquefaciens isolates were $\mathrm{Tet}^{\mathrm{r}}$. Furthermore, all $14 \mathrm{Tet}^{\mathrm{s}} S$. faecalis isolates were late producers of acid from sorbitol, i.e., positive reactions were recorded after $72-96 \mathrm{~h}$ as against $<36 \mathrm{~h}$ for all $\mathrm{Tet}^{\mathrm{r}}$ isolates of $S$. faecalis or $S$. faecalis var. liquefaciens. These find-

Table II. Correlation between biotype and tetracycline susceptibility phenotype of $S$. faecalis isolates from dental plaque

\begin{tabular}{lccc}
\hline $\begin{array}{l}\text { Biochemical* and tetracycline- } \\
\text { susceptibility characteristics }\end{array}$ & $\begin{array}{c}\text { Biotype I } \\
(\mathrm{n}=12)\end{array}$ & $\begin{array}{c}\text { Biotype II } \\
(\mathrm{n}=4)\end{array}$ & $\begin{array}{c}\text { Biotype III } \\
(\mathrm{n}=14)\end{array}$ \\
\hline $\begin{array}{l}\text { Acid production from: } \\
\text { Inositol }\end{array}$ & + & - & - \\
$\quad$ Sorbitol $\dagger$ & ++ & ++ & + \\
$\quad$ Sucrose & + & - & + \\
$\quad$ Xylose & - & + & - \\
Gelatin liquefaction & + & - & - \\
Alkaline phosphatase & + & - & - \\
$\beta$-Galactosidase & + & + & - \\
Tetracycline phenotype $\ddagger$ & $\mathrm{R}$ & $\mathrm{R}$ & $\mathrm{S}$ \\
Tetracycline MIC values $(\mu \mathrm{g} / \mathrm{ml}):$ & & & \\
$\quad$ Tetracycline & 64 & $32-64$ & $0 \cdot 25$ \\
Oxytetracycline & 64 & 64 & $0 \cdot 5$ \\
Chlortetracycline & 64 & 64 & $0 \cdot 25$ \\
$\quad$ Doxycycline & 64 & 64 & $0 \cdot 25$ \\
Minocycline & 32 & 32 & $0 \cdot 125$ \\
\hline
\end{tabular}

\footnotetext{
* All isolates were non-haemolytic and produced acid from rhamnose. $+++=$ Rapid production of acid from sorbitol $(24-36 h) ;+=$ slow production of acid from sorbitol $(72-96 \mathrm{~h})$.

$\ddagger R=$ tetracycline-resistant; $\quad S=$ tetracycline-sensitive (Barry and Thornsberry, 1980; Kaye, 1982).
} 
ings prompted a more comprehensive investigation of possible additional differences in biotype between isolates, in conjunction with serotype and phage type determinations.

\section{Biotyping and tetracycline susceptibility}

The $S$. faecalis and $S$. faecalis var. liquefaciens isolates all produced acid from amygdalin, cellobiose, fructose, galactose, glycerol (aerobically and anaerobically), lactose, maltose, mannitol, pyruvate, rhamnose, ribose, sorbitol, starch and trehalose. They all failed to produce acid from arabinose, adonitol, dulcitol, glycogen, inulin, melibiose, mucic acid, raffinose and sorbose. Sugar reactions in the API-20 Strep tests were in complete agreement with broth-sugar tests. None was haemolytic on blood agar nor possessed lysine nor ornithine decarboxylases. With the API-20 Strep Kit, all produced acetoin, hydrolysed aesculin, hippurate and arginine, produced leucine aminopeptidase and lacked $\alpha$-galactosidase and $\beta$-glucuronidase.

Strains could be divided into three biotypes on the basis of standard biochemical tests and the API findings (table II). Moreover, these biotypes correlated with the $\mathrm{Tet}^{\mathrm{r}}$ and $\mathrm{Tet}^{\mathrm{s}}$ phenotypes of strains. All of the tetracycline-resistant isolates produced $\beta$ galactosidase and were rapid producers of acid from sorbitol. Biotype I and biotype II strains (all Tet $^{r}$ ) could be differentiated on the basis of five tests; biotypes I and III and biotypes II and III were distinguished by five and four biochemical markers, respectively, as well as by susceptibility to tetracyclines (table II).

The MIC values for the five tetracycline antibiotics differed between biotypes I and II (Tet $\left.{ }^{r}\right)$ and biotype III $\left(\mathrm{Tet}^{\mathrm{s}}\right)$; MIC values were in the range 32$64 \mu \mathrm{g} / \mathrm{ml}$ for the former and $0 \cdot 125-0.5 \mu \mathrm{g} / \mathrm{ml}$ for the latter. The MIC values for the biotype III strains were compatible with the modal MIC values expected with the more susceptible strains of $S$. faecalis (Barry and Thornsberry, 1980; Kaye, 1982).

\section{Phage typing and serotyping}

The biotypes, phage types and serotypes of the oral isolates of $S$. faecalis are shown in table III. All 12 isolates of biotype I were of phage type $I_{1}$ and Sharpe and Shattock serotype 1, and represent a clearly definable group. Strains of biotypes II and III were all of phage type $V_{6 b}$ and were non-typable with the eight serotype-specific sera available, with three exceptions - strains 17004S, 17009S and $18005 \mathrm{~S}$ - each of which belonged to biotype III and serotype 19.
Epidemiology of enterococci amongst haemodialysis patients

Tables I and III show that oral S. faecalis isolates with the biotype/phage type/serotype combinations $\mathrm{I} / \mathrm{I}_{1} / 1$ and III $/ \mathrm{V}_{6 \mathrm{~b}} / \mathrm{NT}$ occurred with approximately equal frequency within the control University personnel and in patients with toothache as well as in the combined haemodialysis out-patient groups and the combined dialysis unit staff attending outpatients (subjects and strain numbers beginning with 11 and 12,13 and 15 , and 14 and 16 , respectively).

Three of the outpatients and one of the attendant

Table III. Biotype, phage type and serotype of 30 isolates of $S$. faecalis from dental plaque

\begin{tabular}{|c|c|c|c|}
\hline Strain no. & Biotype* & Phage type $†$ & $\begin{array}{l}\text { Group D } \\
\text { serotype }\end{array}$ \\
\hline $11018 \mathrm{~S}$ & III & $V_{6 b}$ & NT \\
\hline $11018 \mathrm{R}$ & I & $\mathbf{I}_{1}$ & 1 \\
\hline $11025 R$ & I & $\mathrm{I}_{1}$ & 1 \\
\hline $11027 \mathrm{~S}$ & III & $V_{6 b}$ & NT \\
\hline $12019 \mathrm{~S}$ & III & $V_{6 b}$ & NT \\
\hline $12019 \mathrm{R}$ & I & $\mathrm{I}_{1}$ & 1 \\
\hline $12038 \mathrm{~S}$ & III & $V_{6 b}$ & NT \\
\hline $12038 \mathrm{R}$ & I & $\mathrm{I}_{1}$ & 1 \\
\hline $12054 \mathrm{R}$ & I & $\mathrm{I}_{1}$ & 1 \\
\hline $13002 \mathrm{~S}$ & III & $V_{6 b}$ & NT \\
\hline 13002R & I & $\mathrm{I}_{1}$ & 1 \\
\hline $13008 \mathrm{~S}$ & III & $V_{6 b}$ & NT \\
\hline $13008 \mathrm{R}$ & II & $V_{6 b}$ & NT \\
\hline $13043 \mathrm{~S}$ & III & $V_{6 b}$ & NT \\
\hline 13043R & I & $\mathbf{I}_{1}$ & 1 \\
\hline $14002 S$ & III & $V_{6 b}$ & NT \\
\hline $15006 \mathrm{R}$ & II & $V_{6 b}$ & NT \\
\hline $15010 \mathrm{R}$ & II & $V_{6 b}$ & NT \\
\hline $16005 R$ & I & $\mathbf{I}_{1}$ & 1 \\
\hline $17001 \mathrm{~S}$ & III & $V_{6 b}$ & NT \\
\hline $17001 \mathrm{R}$ & I & $\mathrm{I}_{1}$ & 1 \\
\hline $17002 \mathrm{R}$ & I & $\mathbf{I}_{1}$ & 1 \\
\hline 17003R & I & $\mathrm{I}_{1}$ & 1 \\
\hline $17004 S$ & III & $V_{6 b}$ & 19 \\
\hline $17009 \mathrm{~S}$ & III & $V_{6 b}$ & 19 \\
\hline $18003 \mathrm{~S}$ & III & $V_{6 b}$ & NT \\
\hline 18003R & II & $V_{6 b}$ & NT \\
\hline $18004 \mathrm{~S}$ & III & $V_{6 b}$ & NT \\
\hline $18004 \mathrm{R}$ & I & $\mathrm{I}_{1}$ & 1 \\
\hline $18005 \mathrm{~S}$ & III & $V_{6 b}$ & 19 \\
\hline
\end{tabular}

* Biotype designations according to table II. † Subscripts indicate subtypes: phage type $I_{1}$ strains are lysed by phages 1 and 2 of the standard set, whereas strains of phage type $V_{6 b}$ are lysed by phages $5,10,11,12,13,14,15$ and 17.

$\ddagger \mathrm{NT}=$ not typable with antisera to Sharpe and Shattock sero-types $1,3,4,5,6,8,9$ and 19 . 
nurses at the haemodialysis clinic of hospital D harboured strains with the biotype/phage type/ serotype combination III/ $/ \mathrm{V}_{6 \mathrm{~b}} / \mathrm{NT}$ and two of the remaining three outpatients carried $S$. faecalis of the $\mathrm{I} / \mathrm{I}_{1} / 1$ phenotype combination. However, it was not possible retrospectively to work out the frequency of contact between these individuals at the time of the bacteriological survey (Smyth et al., 1986) once these typing data became available. Staff and outpatients at hospital $\mathrm{X}$ were not colonised with $S$. faecalis possessing identical typing combinations. No isolate with the biotype/phage type/serotype combination $\mathrm{I} / \mathrm{I}_{1} / 1$ was obtained from outpatients or staff at hospital X.

Three of the strains characterised by the biotype/ phage type/serotype combination II/ $\mathrm{V}_{6 \mathrm{~b}} / \mathrm{NT}$, i.e., strains 13008R, 15006R and 15101R, were from haemodialysis outpatients, two of whom attended the same clinic. Patient 13008, who attended a separate haemodialysis clinic, had had no known contact with these latter two patients. The dialysis unit nurse 18003 at hospital $\mathrm{H}$ who carried $S$. faecalis with the same typing combination had not been in attendance at either of the two clinics visited by these three haemodialysis outpatients.

Among the combined haemodialysis inpatients and dialysis unit staff at hospital $\mathrm{H}$, the overall ratio of strains of typing combinations $\mathrm{I} / \mathrm{I}_{1} / 1$ and III $/ \mathrm{V}_{6 \mathrm{~b}} /$ NT did not differ from those in the above groups. However, all three of the isolates of typing combination III $/ V_{6 b} / 19$ were from subjects in this hospital, two patients and one nurse. Moreover, three inpatients and one of the attendant staff yielded $S$. faecalis of the typing combination $\mathrm{I} / \mathrm{I}_{1} / 1$, and one patient and two staff $S$. faecalis of the typing combination III $/ \mathrm{V}_{6 \mathrm{~b}} / \mathrm{NT}$. Precise contact data between these individuals were unavailable by the time the complete biotype/phage type/serotype combinations of strains became known.

\section{Characterisation of $S$. faecalis strains of phage type $I_{1}$ from clinical sources}

Since a survey of 441 German strains of $S$. faecalis from different clinical sources had revealed only 19 strains $(4 \cdot 3 \%)$ of phage type $\mathrm{I}_{1}$ (Brandis et al., 1985), a number of these were examined for biotype, phage type, serotype and tetracycline susceptibility (tables IV and V).

Eight of the 13 isolates were similar in biotype to oral strains of biotype-I, but lacked alkaline phosphatase and $\beta$-galactosidase as detected in the API tests. Of these eight, six were also $\beta$-haemolytic. This biotype was designated biotype $\mathrm{I}^{1}$. The remain-
Table IV. Biotypes of 13 clinical isolates of $S$. faecalis of phage type $\mathbf{I}_{1}$

\begin{tabular}{lccc}
$\begin{array}{l}\text { Biochemical } \\
\text { characteristics }\end{array}$ & $\begin{array}{c}\text { Biotype } \mathrm{I}^{1} \\
(\mathrm{n}=8)\end{array}$ & $\begin{array}{c}\text { Biotype IV } \\
(\mathrm{n}=4)\end{array}$ & $\begin{array}{c}\text { Biotype V } \\
(\mathrm{n}=1)\end{array}$ \\
\hline $\begin{array}{l}\text { Acid production from: } \\
\quad \text { Inositol }\end{array}$ & + & + & + \\
$\quad \begin{array}{l}\text { Sorbitol } \\
\text { Sucrose }\end{array}$ & ++ & ++ & ++ \\
$\quad$ Xylose & + & + & + \\
$\begin{array}{l}\text { Gelatin liquefaction } \\
\text { Alkaline phosphatase }\end{array}$ & + & + & + \\
$\beta$-Galactosidase & - & - & + \\
Acid from rhamnose* & + & - & - \\
$\beta$-Haemolysis* & $-{ }^{2}$ or ${ }^{2}{ }^{6}$ & $-{ }^{2}$ or or $+{ }^{2}$ & + \\
& & & + \\
\hline
\end{tabular}

* Superscripts indicated the number of isolates with the indicated property.

ing five strains differed from all others examined in that they produced acid from both inositol and xylose. Three of these five isolates were $\beta$-haemolytic. They were divided into two biotypes, designated IV and $\mathrm{V}$, on the basis of the $\beta$-galactosidase test and gelatin liquefaction. Moreover, two strains of biotype IV did not produce acid from rhamnose.

When the serotypes of the German phage-type $I_{1}$ isolates were determined, 10 of the 13 strains belonged to Sharpe and Shattock type 1 (table V). Within this phage type/serotype combination, two biotypes were represented, but neither correlated with the clinical source of isolates nor with tetracycline susceptibility (table V).

Typing of reference $S$. faecalis strains and the single $S$. durans oral isolate

S. faecalis strain ATCC 19433 possessed a Tet ${ }^{\mathrm{s}}$ phenotype and was identical in biotype, serotype and phage type to the tetracycline-sensitive isolates of oral origin (tables II, III and V).

$S$. faecalis strain M439 had a biochemical profile identical to oral Tet ${ }^{\mathrm{r}}$ isolates of biotype I, but was $\beta$ haemolytic, belonged to a different phage-type, and was non-typable with the available antisera (table V). Strain M440 was also $\beta$-haemolytic, had a biochemical profile almost identical to biotype-I strains, but it did not produce acid from rhamnose, belonged to phage type $V_{6 b}$ and was non-typable serologically.

$S$. durans strain 15006 possessed a biochemical test profile identical to that reported for the majority of strains of this species by Colman and Ball (1984) with the API-20 Strep Kit and by Facklam (1972) and Gross et al. (1975) with conventional 
Table V. Properties of 13 German clinical isolates of S. faecalis of phage type $I_{1}$ and of reference strains of $S$. faecalis

\begin{tabular}{|c|c|c|c|c|c|}
\hline Strain no. & Source & $\begin{array}{l}\text { Tetracycline } \\
\text { susceptit.lity } \\
\text { (MIC ug nl) }\end{array}$ & Biotype & $\begin{array}{l}\text { Phage } \\
\text { type }\end{array}$ & $\begin{array}{c}\text { Group-D } \\
\text { serotype }\end{array}$ \\
\hline \multicolumn{6}{|l|}{ Clinical } \\
\hline AP3 & Urine & 0.5 & IV & $I_{1}$ & 1 \\
\hline AP8 & Urine & 128 & $\mathbf{I}^{1}$ & $\mathrm{I}_{1}$ & 1 \\
\hline AP41 & Vaginal swab & 0.5 & $\mathrm{I}^{1}$ & $\mathrm{I}_{1}$ & 1 \\
\hline AP46 & Urine & $0 \cdot 5$ & $I^{1}$ & $I_{1}$ & 1 \\
\hline AP91 & Urine & 0.5 & $I^{1}$ & $I_{1}$ & 9 \\
\hline AP168 & Umbilical swab & 0.5 & $I^{1}$ & $\mathbf{I}_{1}$ & NT \\
\hline AP229 & Wound swab & $0 \cdot 5$ & IV & $\mathrm{I}_{1}$ & 1 \\
\hline AP280 & Urine & 0.5 & IV & $\mathrm{I}_{1}$ & 1 \\
\hline AP286 & Urine & 64 & $\mathrm{~V}$ & $\mathrm{I}_{1}$ & NT \\
\hline AP393 & Vaginal swab & 0.5 & $\mathbf{I}^{1}$ & $\mathrm{I}_{1}$ & 1 \\
\hline AP410 & Urine & 64 & $I^{1}$ & $\mathrm{I}_{1}$ & 1 \\
\hline AP429 & Urine & 64 & $\mathbf{I}^{1}$ & $\mathrm{I}_{1}$ & 1 \\
\hline AP459 & Urine & 64 & IV & $\mathrm{I}_{1}$ & 1 \\
\hline \multicolumn{6}{|l|}{ Reference strains } \\
\hline ATCC19433 & & 0.25 & III & $V_{6 b}$ & NT \\
\hline M439 & Clinical & 64 & I & $\mathrm{V}_{4}$ & NT \\
\hline M440 & Clinical & 64 & I & $V_{6 b}$ & NT \\
\hline
\end{tabular}

$\mathrm{NT}=$ not typable.

biochemical tests. The strain belonged to phage type XX.

Serogrouping for the presence of group- $D$ and group- $G$ antigens

Reports that $S$. faecalis strains possessing Lancefield group-G as well as group-D reactivity showed delayed sorbitol fermentation (Birch et al., 1984, 1985 ) prompted examination of the oral $S$. faecalis isolates for both antigens.

Although all 30 oral stains reacted with the Streptex ${ }^{\circledR}$ and Phadebact ${ }^{\circledR}$ group-D streptococcus reagents and with group $D$ antiserum in precipitin ring tests with various extracts, no extract of these oral isolates reacted with the Streptex ${ }^{\circledR}$ group G reagent or with streptococcal group $\mathrm{G}$ antiserum in conventional precipitation tests. Strain ATCC 19433, also a slow sorbitol fermenter, did not react with the group- $G$ reagents.

\section{Discussion}

It is often implied that most enterococcal infections are acquired from the patient's own flora. Enterococci are frequently present in the vagina and anterior urethra and are numerous in faeces. They are isolated from urinary tract, pelvic and intraabdominal infections (Shulman, 1979; Facklam and Carey, 1985). Because of the association of enterococci with endocarditis (Mandell, 1976), the report of Campbell et al. (1983) that oral carriage of enterococci was significantly higher in chronic hospital patients, including haemodialysis patients, with an implied risk of infection following dental manipulation, led to an investigation of this claim in haemodialysis patients in the Dublin area (Smyth $e t$ al., in press) and to the characterisation of the oral isolates obtained.

Although clinical isolates of $S$. faecalis and $S$. faecium from various sources have been serotyped or phage-typed (Sharpe and Shattock, 1952; Plećeaš, 1967, 1982; Brandis et al., 1985), oral isolates of enterococci have commonly only been speciated or described as varieties (Williams et al., 1950; Winkler and Van Amerongen, 1959; Gold et al., 1975; Campbell et al., 1983). Thus, although oral carriage of enterococci is by no means a novel finding, detailed data on the biotypes, antibiotic susceptibility phenotypes, serotypes and phage types of such strains have not been available previously. However, Nátkin (1967) showed that phage typing of enterococcal isolates from the oral cavity could be useful. 
One of the features of the oral $S$. faecalis isolates obtained in the Dublin area was that, despite there being three definable biotypes, two tetracycline susceptibility phenotypes, two phage types and three serotypes including non-typable, only four combinations of these properties were found (table III). Hitherto no comprehensive attempt has been made to study biotype/phage type/serotype combinations among strains from one single defined clinical source or site of carriage. The present findings suggest that the epidemiology of infections due to enterococci might be tackled by such a tripartite typing approach.

Indications were obtained in two instances of the possible spread of strains between patients or between patients and staff. Patients 15006 and 15010 were the only outpatients out of 21 attending the haemodialysis clinic of hospital $\mathrm{X}$ to yield oral enterococci (Smyth et al., in press). These isolates possessed the same uncommon biotype/phage type/ serotype profile, which was found in only four out of the 30 oral $S$. faecalis isolates examined. In the second case, haemodialysis inpatients 17004 and 17009 in hospital $\mathrm{H}$ and the attendant nurse 18005 harboured strains with the same biotype/phage type/serotype combination which was not found in any of the other subjects or clinics. It seems possible in the latter instance that the inevitable close contact between these two inpatients and the nurse could have led to the transfer of one strain.

Although $S$. faecalis of the biotype/phage type/ serotype combination III/ $/ \mathrm{V}_{6 \mathrm{~b}} / \mathrm{NT}$ were isolated from both patients and staff at hospitals $D$ and $H$ and $S$. faecalis with the typing profile $\mathrm{I} / \mathrm{I}_{1} / 1$, from patients and staff at hospital $\mathrm{H}$, such strains occurred with equal incidence in both a University personnel group and a group of patients with toothache investigated as control subjects (tables I and III; Smyth et al., in press). These findings in the hospital groups may, thus, only reflect the natural oral incidence of such strains rather than spread between patients or between patients and staff. A further degree of strain differentiation, such as enterocine typing (Plećeaš et al., 1972), would be required to clarify any epidemiological relationships. Tetracycline susceptibility may not be a particularly useful marker because tetracycline resistance is associated with the presence of a plasmid or a transposon (Clewell, 1981; Clewell et al., 1985).

All but four of the Tet $^{\mathrm{r}}$ strains were identified as S. faecalis var. liquefaciens according to accepted criteria (Cowan, 1974; Facklam, 1972). All possessed the same biotype, phage type and serotype profile $I / I_{1} / 1$. Because the phage subtype $I_{1}$ was relatively rare among German clinical isolates (Brandis et al., 1985), several of these were investigated. Excluding haemolytic properties of strains which have been shown to be determined by transmissible plasmids (Dunny and Clewell, 1975; Jacob et al., 1975), eight of these clinical isolates differed in only two biochemical characters from the oral biotype-I isolates; six of these belonged to the Sharpe and Shattock serotype 1. Of the remaining five clinical isolates of $S$. faecalis of phage type $\mathrm{I}_{1}$ four were of serotype 1, but possessed a distinct biotype not seen in any of the oral isolates. Thus, the biotype findings for isolates with the phage type/ serotype combination $I_{1} / 1$ indicate that biotyping offers a degree of discrimination among such strains; it may, however, be possible that isolates are of a similar biotype in a single geographical location, i.e., Irish oral isolates were of biotype I whereas the German clinical isolates were of biotypes $\mathrm{I}^{1}$ or IV.

The $\beta$-galactosidase test was one of those affected by growth conditions in the extensive study of the API-20 Strep Kit performed by Colman and Ball (1984). Moreover, in the latter study only 49 of $78 S$. faecalis strains tested were positive in the $\beta$-galactosidase test despite producing acid from lactose. In the present study only 22 of 46 lactose-positive strains tested possessed $\beta$-galactosidase. Possible explanations of these findings are that in some strains $\beta$-galactosidase may be inducible, whereas it may be constitutive in others; also, lactose transport into enterococci may occur either by active transport or by group translocation, whereby lactose is phosphorylated and subsequently hydrolysed by a phospho- $\beta$-galactosidase (Kaback, 1970; McKay et al., 1970). Such a group translocation system has been described in Staphylococcus aureus and in lactic acid streptococci.

Fourteen of the oral isolates of $S$. faecalis were late producers of acid from sorbitol. In their study of group-D streptococci from outbreaks of neonatal diarrhoea, Sharpe and Shattock (1952) described slow sorbitol fermentation in two of their type strains. Gross et al. (1975) also described this biochemical phenotype in an unknown proportion of the 546 clinical isolates of $S$. faecalis. Recently, delayed sorbitol fermentation has been reported as a characteristic of $S$. faecalis strains that possessed the Lancefield group-G antigen as well as the group$\mathrm{D}$ antigen (Birch et al., 1984, 1985). Indeed, according to Birch et al. (1985), "delayed sorbitol fermentation occurs only amongst strains from certain geographical areas and has not been encountered in any conventional group D strains". Herein the slow sorbitol-fermenting oral isolates lacked group-G 
antigen and seemed as conventional in other respects as isolates examined by others (Facklam, 1972; Gross et al., 1975; Colman and Ball, 1984; Facklam and Carey, 1985). Thus, slow sorbitol fermentation by itself does not appear to be a definitive phenotypic marker for strains with both group-D and and group-G reactivity.

Although the biotype/phage type/serotype combinations of oral isolates were restricted, it is not known whether these patterns are distinctive for Irish $S$. faecalis isolates from the oral cavity or apply equally to strains of oral origin from broader geographical areas. S. faecalis of phage subtype $\mathrm{V}_{6 \mathrm{~b}}$ were the most common amongst clinical isolates in a German survey (Brandis et al., 1985), as well as amongst oral isolates in Eire. Although most of the latter were of biotype III, the occurrence of four biotype II isolates and the finding that strain M440 was biotype I indicates that biotyping may be useful for discrimination within this phage type for epidemiological purposes.

Enterococcal endocarditis has been reported in six haemodialysis patients, four of whom acquired this condition after dental work (Goodman et al., 1969; Wyler et al., 1972; Cross and Steigbigel, 1976). The risk of endocarditis resulting from dental manipulation in oral carriers of enterococci might be more readily assessed if more information was available on the combined phenotypic markers of isolates from endocarditis cases and those of orally carried isolates.

We thank Sarah Ballagh who isolated the oral enterococcal strains; $H$. Kearns for fulfilling the requests for media efficiently and expeditiously; Jane Twohig and Linda Bradley for technical assistance; Lucia Andries for the phage typing; Gillian Johnston for secretarial work; and D. Shanley for his encouragement and enthusiasm.

\section{REFERENCES}

Anhalt J P, Washington J A 1980 Preparation and storage of antimicrobic solutions. In: Lennette $\mathrm{E} \mathrm{H}$ et al. (eds) Manual of clinical microbiology, 3rd edn. American Society for Microbiology, Washington, D.C., p 495.

Barry A L, Thornsberry C 1980 Approximate minimal inhibitory concentrations of more susceptible strains among common bacterial pathogens. In: Lennette $\mathrm{E} \mathrm{H}$ et al (eds) Manual of clinical microbiology, 3rd edn. American Society for Microbiology, Washington, D.C., p 498.

Birch B R, Keaney M G L, Ganguli L A 1984 Streptococcus faecalis: group D or group G? Lancet 1:856.

Birch B R, Keaney M G L, Ganguli L A, Siegrist H H, Jacob A E 1985 Properties of Streptococcus faecalis possessing group $\mathrm{G}$ antigen. Abstracts of 2 nd European Congress of Clinical Microbiology, Brighton, No. 21/6.

Brandis H, Plećeaš P, Andries L 1985 Die Typisierung von
Streptococcus faecalis- und Streptococcus faecium-Stämmen mit Bakteriophagen. Zentralblatt für Bakteriologie, Mikrobiologie und Hygiene I. Abteilung Originale A 260:206-215.

Campbell J, McGowan D A, Macfarlane T W 1983 The prevalence of enterococci in the dental plaque of chronic hospital patients. British Journal of Oral Surgery 21:171174.

Caprioli T, Zaccour F, Kasatiya S S 1975 Phage typing scheme for group D streptococci isolated from human urogenital tract. Journal of Clinical Microbiology 2:311-317.

Clewell D B 1981 Plasmids, drug resistance, and gene transfer in the genus Streptococcus. Microbiological Reviews 45:409436.

Clewell D B et al. 1985 Streptococcal conjugation: plasmids, sex pheromones, and conjugative transposons. In: Mergenhagen S E, Rosan B (eds) Molecular basis of oral microbial adhesion. American Society for Microbiology, Washington, D.C., p 194.

Collins M D, Jones D 1979 The distribution of isoprenoid quinones in streptococci of serological group D. In: Parker M T (ed) Pathogenic streptococci, Proceedings of the VIIth International symposium on streptococci and streptococcal diseases. Reedbooks Ltd, Chertsey, England, p 249.

Colman G, Ball L C 1984 Identification of streptococci in a medical laboratory. Journal of Applied Bacteriology 57:114.

Cowan S T 1974 Cowan and Steel's Manual for the identification of medical bacteria, 2nd edn. Cambridge University Press, Cambridge, p 51 .

Cross A S, Steigbigel R T 1976 Infective endocarditis and access site infections in patients on hemodialysis. Medicine (Baltimore) 55:453-466.

Deibel R H 1964 The group D streptococci. Bacteriological Reviews 28:330-366.

Dunny G M, Clewell D B 1975 Transmissible toxin (hemolysin) plasmid in Streptococcus faecalis and its mobilisation of a noninfectious drug resistance plasmid. Journal of Bacterio$\log y$ 124:784-790.

Edwards P R, Ewing W H 1972 Identification of Enterobacteriaceae, 3rd edn. Burgess Publishing Company, Minneapolis.

Engel H W B, Van Embden J D A, Van Klingeren B, Soedirman N 1979 Transferable drug resistance in group-A, -B and -D streptococci. In: Parker M T (ed) Pathogenic streptococci, Proceedings of the VIIth International symposium on streptococci and streptococcal diseases. Reedbooks Ltd, Chertsey, England, p 282.

Facklam R R 1972 Recognition of group D streptococcal species of human origin by biochemical and physiological tests. Applied Microbiology 23:1131-1139.

Facklam R R, Carey R B 1985 Streptococci and aerococci. In: Lennette E $\mathrm{H}$ et al. (eds) Manual of clinical microbiology, 4th edn. American Society for Microbiology, Washington D.C., p 154.

Feltham R K A 1979 A taxonomic study of the genus Streptococcus. In: Parker M T (ed) Pathogenic streptococci, Proceedings of the VIIth International symposium on streptococci and streptococcal diseases. Reedbooks Ltd, Chertsey, England, $\mathrm{p} 247$.

Gold O G, Jordan H V, Van Houte J 1975 The prevalence of enterococci in the human mouth and their pathogenicity in animal models. Archives of Oral Biology 20:473-477.

Goodman J S, Crews H D, Ginn H E, Koenig M G 1969 Bacterial endocarditis as a possible complication of chronic hemodialysis. New England Journal of Medicine 280:876877.

Gross K C, Houghton M P, Senterfit L B 1975 Presumptive speciation of Streptococcus bovis and other group D 
streptococci from human sources by using arginine and pyruvate tests. Journal of Clinical Microbiology 1:54-60.

Hérmán G, Hoch V 1971 Phage-typing of group D streptococci. II. Isolation of supplementary phages for classification of enterococci untypable with Roumanian phages. Acta Microbiologica Academiae Scientiarum Hungaricae 18:101-104.

Hoch V, Hérmán G 1971 Phage-typing of group D streptococci. I. Typing of enterococci with Roumanian phages. Acta Microbiologica Academiae Scientiarum Hungaricae 18:9599.

Hopfer R L, Pinzon R, Wenglar M, Rolston K V 1985 Enzyme release of antigen from Streptococcus faecalis and Listeria monocytogenes cross-reactive with Lancefield group $\mathbf{G}$ typing reagents. Journal of Clinical Microbiology 22:677679.

Jacob A E, Douglas G J, Hobbs S J 1975 Self-transferable plasmids determining the hemolysin and bacteriocin of Streptococcus faecalis var. zymogenes. Journal of Bacterio$\log y$ 121:863-872.

Jones D 1978 Composition and differentiation of the genus Streptococcus In: Skinner F A, Quesnel L B (eds) Streptococci, Society for Applied Bacteriology Symposium Series No. 7. Academic Press, London, p 1.

Jones D, Sackin M J, Sneath P H A 1972 A numerical taxonomic study of streptococci of serological group D. Journal of General Microbiology 72:439-450.

Kaback H R 1970 Transport. Annual Review of Biochemistry 39:561-598.

Kaye D 1982 Enterococci: biologic and epidemiologic characteristics and in vitro susceptibility. Archives of Internal Medicine 142:2006-2009.

Mandell G L 1976 Enterococcal endocarditis. In: Kaye D (ed) Infective endocarditis. University Park Press, Baltimore, $\mathrm{p}$ 101.

McKay L, Miller A, Sandine W E, Elliker P R 1970 Mechanisms of lactose utilization by lactic acid streptococci: enzymatic and genetic analyses. Journal of Bacteriology 102:804-809.

Møiler V 1955 Simplified tests for some amino acid decarboxylases and for the arginine dihydrolase system. Acta Pathologica et Microbiologica Scandinavica 36:158-172.

Nátkin E 1967 Isolation and host range of bacteriophages active against human oral streptococci. Archives of Oral Biology 12:669-680.

Parker M T, Ball L C 1976 Streptococci and aerococci associated with systemic infection in man. Journal of Medical Microbiology 9:275-302.

Plećeaš P 1967 Typage sérologique du Streptococcus faecalis. Archives Roumaines de Pathologie Expérimentale et de Microbiologie 26:405-410.

Plećeaš P 1979 A phage-typing system for Streptococcus faecalis and Steptococcus faecium. In: Parker M T (ed) Pathogenic streptococci, Proceedings of the VIIth International sym- posium on streptococci and streptococcal diseases. Reedbooks Ltd, Chertsey, England, p 264.

Plećeaš P 1982 Lysotyping of enterococci isolated from urinary tract infection cases. In: Holm S E, Christensen P (eds) Basic concepts of streptococci and streptococcal diseases, Proceedings of the VIIIth International symposium on streptococci and streptococcal diseases. Reedbooks Ltd, Chertsey, England, p 56.

Plećeaš $\mathrm{P}$, Brandis H $1974 a$ Rapid group and species identification of enterococci by means of tests with pooled phages. Journal of Medical Microbiology 7:529-533.

Plećeaš P, Brandis H $1974 b$ Différenciation des principales espèces de streptocoques du groupe D par les mélanges de bactériophages spécifiques. Annales de Microbiologie (Institut Pasteur) 125B:463-470.

Plećeaš P, Racovita C, Thomas E, Epuran E 1968 Typage sérologique des entérocoques isolés dans des cas d'infections urinaires. Archives Roumaines de Pathologie Expérimentale et de Microbiologie 27:303-308.

Plećeaš P, Bogdan C, Vereanu A 1972 Enterocine-typing of group D streptococci. Zentralblatt für Bakteriologie, Mikrobiologie und Hygiene I. Abteilung Originale A 221:173-188.

Sharpe M E, Shattock P M F 1952 The serological typing of group D streptococci associated with outbreaks of neonatal diarrhoea. Journal of General Microbiology 6:150-165.

Shulman J A 1979 Streptococcus faecalis and other enterococci. In: Mandell G L et al. (eds) Principles and practice of infectious diseases. John Wiley and Sons Inc., New York, p 1605.

Smyth C J, Halpenny M K, Ballagh S 1986 Carriage rates of enterococci in the dental plaque of haemodialysis patients in Dublin. British Journal of Dental Surgery in press.

Van Embden J D A, Engel H W B, Van Klingeren B 1977 Drug resistance in group D streptococci of clinical and nonclinical origin: prevalence, transferability, and plasmid properties. Antimicrobial Agents and Chemotherapy 11:925-932.

Washington J A, Sutter V L 1980 Dilution susceptibility test: agar and macro-broth dilution procedures. In: Lennette $\mathrm{E} \mathrm{H}$ et al. (eds) Manual of clinical microbiology, 3rd edn. American Society for Microbiology, Washington, D.C., p 453.

Williams N B, Forbes M A, Blau E, Eickenberg C F 1950 A study of the simultaneous occurrence of enterococci, lactobacilli, and yeasts in saliva from human beings. Journal of Dental Research 29:563-570.

Winkler K C, Van Amerongen J 1959 Bacteriologic results from 4000 root canal cultures. Oral Surgery, Oral Medicine and Oral Pathology 12:857-875.

Wyler D J, Golde D W, Grausz H 1972 Bacterial endocarditis in a patient with a saphenous vein graft A-V fistula receiving dental work. California Medicine 117:75-76. 